\title{
Scientists stumped by test that promises tailored treatment
}

For nine out of ten people with severe pain, codeine can be a godsend. But because of genetic differences, in that remaining one person, codeine is powerless. New diagnostic tests promise to help doctors easily identify that one patient before prescribing the drug-but only if they can first learn to read the tests.

Patients with conditions such as pain, heart disease and depression routinely endure months of trial and error before doctors can determine the drug and dose that works for them. In the US alone, adverse reactions to drugs cause upwards of 100,000 deaths each year. Researchers are exploiting advances in gene detection technology to develop tests for genes such as those that encode the cytochrome P450 (CYP450) family of liver enzymes, which affect how the body metabolizes drugs.

In September, the European Commission certified Roche Diagnostics' AmpliChip CYP450, the first test available for clinical use. In the US, several companies use such tests as research tools, but the Food and Drug Administration in 2003 denied Roche's application to market AmpliChip clinically, saying more safety and efficacy trials are needed.

Amplichip detects different alleles of two key genes related to CYP450. For example, the enzyme produced by the CYP2D6 gene breaks

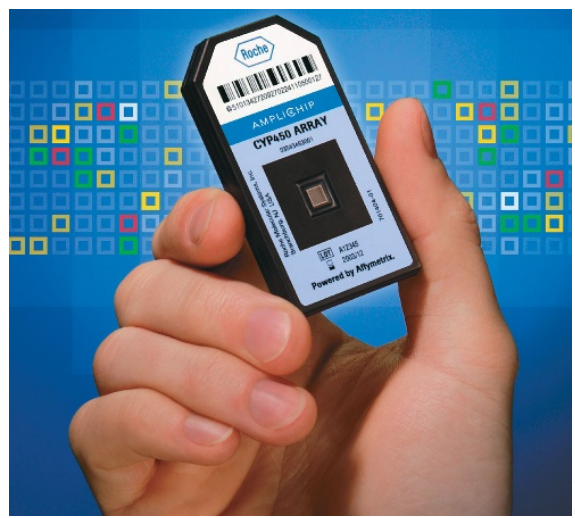

This test could help predict the right dose for a drug.

down antidepressants. A particular allele of the gene might predict that the individual's ability to metabolize the antidepressant is only half the normal level. But does that mean that the patient should take only half the regular dose of antidepressant? The tests don't answer that important question.

"The technology is way ahead of the clinical knowledge," says Howard McLeod, who studies genetic differences in responses to cancer drugs at Washington University in St. Louis. "There's still this difficulty of what to do when we have the result. There are guidelines out there, but they're really based not on fact but on supposition."

Others say enough is known to make these tests clinically valuable. "It isn't rocket science," says David Mrazek, chair of psychiatry and psychology at the Mayo Clinic in Rochester. Mrazek teaches week-long seminars for clinicians on the genetics of psychiatry. "If [doctors] can just understand that poor metabolizers are likely to experience side effects and rapid metabolizers won't get efficacy from a standard dose, that's enough," he says.

Mrazek says his department has been using a homebrew test for CYP2D6 since February 2003 and has made it available to clinicians outside of Mayo beginning in March 2004. Meanwhile, Roche researchers say that now that a test is commercially available, they can begin to gather the data needed to translate test results into dose recommendations. Roche says as many as nine clinical trials of AmpliChip are under way in the US and Europe.

Although companies use the tests to select patients for clinical trials, they are reluctant to validate the tests' use in the clinic because that would limit the market for a drug, critics charge. "There's been little interest, if not discouragement [from companies]," says Mrazek. "I've become a little jaded by the process."

Alla Katsnelson, New York

\section{Database draws attention to not-so-Nobel intentions}

For the first time since 1995, the Karolinska Institute in Sweden has added a woman to the short list of female winners of the Nobel Prize in Physiology or Medicine. A database of more than 4,300 nomination letters available on the institute's website in part explains the dominance of male winners in the field.

On 4 October, the Nobel Assembly awarded the SEK10 million (\$1.4 million) prize to US researchers Linda Buck and Richard Axel for deciphering how mammals, including humans, identify thousands of smells. Buck is the seventh woman to win in the category since 1901 , adding up to just $4 \%$ of 182 winners.

Reviewers at the Karolinska Institute have in the past attributed that scarcity to male dominance within the biomedical field. The institute's database supports that assertion. Covering only the years 1901-1949 because of confidentiality rules, it reveals that only $1.2 \%$ of nomination letters mentioned 12 different female nominees. Of those, biochemist Gerty T. Cori became the lone female winner among 56 laureates over that period. University of Chicago bacteriologist Gladys Dick, together with her husband George Dick, was nominated by 24 colleagues for findings on scarlet fever, but never got the award.

What's more, only $0.3 \%$ of nominations came from women. Many female scientists at the time couldn't get formal research positions, a prerequisite to be invited to nominate, says Sharon McGrayne, author of the book Nobel Prize Women in Science. "Through the years, many factors have come together on many levels, making the problems of women in science such a persistent thing," she says.

Even now, boosting female representation is difficult because professorial positions in many countries are still occupied mostly by men, notes Hans Jörnvall, the Assembly's secretary. "We can't dictate whom people should nominate," he says.

The selection process for Nobel Prizes has historically been a heavily guarded secret. Nomination letters, evaluations and deliberations are kept secret for 50 years, and only qualified researchers are allowed access to documents from earlier years. The Karolinska Institute, which awards the Physiology or Medicine Prize, was the first to go online in 2002 with a searchable nomination database.
The records offer details such as gender, university, city and country of nominators and nominees, and indicate whether and by whom the nomination was evaluated. The database also reveals that, at least up to 1949, researchers from Japan, the US and France primarily nominated scientists from their own countries. Jörnvall says it is unclear whether the database will continue to be updated.

Israelis Aaron Ciechanover and Avram Hershko and American Irwin Rose shared the 2004 Chemistry Prize for discovering how cells dispose of unwanted proteins. Controversy erupted over Peace Prize winner Wangari Maathai, Kenya's deputy minister for environment and natural resources, who was quoted in a Kenyan newspaper as saying that HIV "is a tool to control [Africans or black people] designed by some evil-minded scientists.”

Peter Vermij, Amsterdam

For more nows and analyals go to news@nature.com win.nature.comhewe 